\title{
Cultural Ecology and City Image Shaping in Zhuhai
}

\author{
Ruihui $\operatorname{Han}^{1}$ \\ ${ }^{1}$ Humanities School, Jinan University, Zhuhai, China \\ Correspondence: Ruihui Han, Humanities School, Jinan University, Zhuhai, Guangdong Province, China. E-mail: \\ hanruihuihh@hotmail.com
}

Received: November 13, 2013 Accepted: December 6, 2013 Online Published: January 27, 2014

doi:10.5539/ass.v10n3p94

URL: http://dx.doi.org/10.5539/ass.v10n3p94

\begin{abstract}
Economic and commercial modernization does not mean the rise in the sense of happiness. This is a problem faced by many courtiers and regions in modern society. The city is the center of human civilization activities. The city is not just at economic and material layer, but also at cultural and spiritual layer. Protection, utilization and development of cultural ecology of a city provide the driving force for sustainable development. Zhuhai is a tourist city with beautiful scenery. In this city, immigrants occupy the overwhelming majority. Thus, it owns profound humanity history resources. During economic construction and development of cultural industry, it is required to maintain cultural ecology and build spiritual home of Zhuhai.
\end{abstract}

Keywords: cultural ecology, city image, Zhuhai

In 2011, Zhuhai successfully registered to be a "City of Happiness". According to the evaluation of city image by people out of Zhuhai, Zhuhai is mainly positioned to a tourist city; in accordance with the evaluation of Zhuhai citizens, city appearance, the quality of residents and government image gain the highest scores. (Yang, G., \& Chen, 2005) Zhuhai is the sole national resort district named after the whole city in China.

In recent years, Zhuhai has obtained excellent results in urban planning and construction and natural environmental protection. Except natural material environment, a city must have socio-cultural environment. Optimization of socio-cultural environment plays a great role in improving Zhuhai city image. In current society, the increase in modern scientific and technological level and capital profit does not mean the rise in the sense of happiness. The sense of happiness is at spiritual level rather than at material level. The improvement of individual ad social quality at spiritual level not just can enhance the sense of happiness, but also is the driving force of sustainable development.

\section{Doubts in Modern Time}

In the $20^{\text {th }}$ century, Adorno (the representative of Frankfurt school in Germany) considered: in modern society, culture had lost its criticism function and gradually degenerated to the toy of commodity rules; it could not resist rational erosion. Most scholars in Frankfurt school support the ideas similar to Adorno's. In their opinions, the arrival of modern industrial society forces culture to become industrialized increasingly. In the ear when commodity economy develops increasingly, consumerism prevails, thus leading to cultural dissimilation.

Adorno's idea is common in western cultural criticism history. For example, in the $19^{\text {th }}$ century, Nietzsche considered modern culture was the product of "a morbid society" and that real culture had been nibbled by commercialism early; in the $18^{\text {th }}$ century, Rousseau in the face of the emergence of modern civilization shouted the slogan of "return to nature". Besides, there were many voices in the literary circle. For example, British writers D.H. Lawrence and Hardy opposed erosion of traditional British social culture by industrialization. They disclosed disasters brought to the society and human by industrialized society in representative works such as Sons and Lovers and Tess of the d'Urbervilles.

A centenary ago, E.A. Ross, the founder of American sociologists, foresaw China's current social situations. In 1911, E.A. Ross published his works The Changing Chinese. In his opinion, future China might become rich, but China might encounter problems in moral consciousness. E.A. Ross found China at that time was canceling imperial examination system, but "whence will come the morality of tomorrow? In the reaction against the old classical education with its emphasis on ethics there has been a tendency to neglect instruction in morals."'(Ross, 1911, p. 342) Thus, "What they covet is riches and power; and, perceiving that the wealth and martial prowess of the West rests immediately upon exact knowledge, the students are all for science. The hidden moral foundations 
of Western success they are apt to overlook. Neglecting their own idealism and missing ours, they may develop a selfish materialistic character which will make the awakening of China a curse instead of a blessing." (Ross, 1911, p. 343)

The opinion of E.A. Ross is of great foreseeability. In current China, over-strong material pursuit often causes people neglect other things. According to public opinion poll of World Journal on February 22, 2010, among 23 countries in the world, the people in China, Japan and Korea most believed "money talks". The three countries were considered as "money worship" countries in the world. The investigation of World Wide Web showed $80 \%$ netizens considered Chinese people the most mammonish crowd in the world. (Zhu, 2010) This can be seen from the following aspects: stressing money in Chinese-style blind date, heavy description of workplace coping skills in popular workplace novels and worship of luxuries. "Money worship is a decayed outlook on life. It sums up all life significance, objectives and values as money pursuit. It is a kind of egoism." (Chen, 2004)

Adorno divided culture into two types: elegant culture resisting commercialization and vulgar culture under rules of commodity exchange. The so-called vulgar culture mainly referred to culture industry. In Adorno's opinion, under synergistic effect of mass media and exquisite technical effect, the products produced by culture industry were machine-made. These products were inundated with superficial aesthetic taste without individuality and provide false joys. Adorno considered the products made by culture industry were in fact a type of frauds. Culture industry hollowed out people's inner rich spiritual life and increasingly controlled people's spiritual world. Although material life is richer than before, the oppression of spiritual life is meanwhile caused. Therefore, great richness of materials and developed culture industry do not means the rise in happiness index.

"The spiritual life of most contemporary people in materialized environment is in 'sub-health status'. The reason why people often describe their feelings with such words as depressed, fickle, bored, anxious, cowardly, gloomy, disappointed, tired, helpless, lonely, confused, abandoned, absurd and despairing is that these words represent their daily status of spiritual life in modern times." (Zou, 2007) Modern civilization not just brings happiness, but also gives rise to negative effects. These can be seen in some western developed capitalist countries. Western modernist literature mostly reflects such emotional status.

\section{Zhuhai in Imagination}

Zhuhai is a tourist city and also immigrant city since China's reform and opening-up. People neglect the history and humanity of Zhuhai for a long time. Thus, Zhuhai fails to establish cultural wholeness. As an immigrant city, some immigrants do not generate strong sense of identity of Zhuhai. They always consider they are immigrants who work and live in Zhuhai. In their narration of Zhuhai, Zhuhai is always regarded as "the other". In some writers' works in Zhuhai, they regard Zhuhai as "a strange place" rather than hometown and narrate the success and failure of the leading characters in Zhuhai.

This imagination can be found in the works of Wang Hailing, Pei Bei, Yang Xueping and other writers in Zhuhai. In their works, Zhuhai is imagined as a world where people work for money, full of scenes of debauchery, mawkishness and hopelessness. Although literature is the product of imagination, it can more easily reflect the impression on something in people's inner world. It sketched people's inner world rather the external world. A city exists in people's imagination rather than physically, because a city is composed of people. All cities serve for people and are built by people. Different city imaginations can create different city images. The culture of a city is an important constituent part of this city and decides future city development.

Compared with some modern cities with rapid development of economy, Zhuhai is still full of countryside style. In modern times, highly-development commerce has been regarded as the representation of city modernization. Zhuhai cannot break away from this historical trend. In the modernization process, spiritual crisis may also occur in Zhuhai.

As an immigrant city, Zhuhai culture is forming. Formation of a favorable socio-cultural atmosphere is particularly important for regional development. Zhuhai should attach importance to formation of such socio-cultural atmosphere. Immigrants in Zhuhai will settle down here and multiply in future decades. Cultural ecology will gradually form and become stable.

\section{Profound Deposits of Humanity History in Zhuhai}

Zhuhai does not lack deposits of humanity history. Firstly, Zhuhai belongs to Lingnan culture traditionally. Lingnan culture in Chinese culture is mainly classified into Cantonese culture, Chaozhou culture and Hakka culture which are centered with Guangzhou, Chaoshan and Meizhou respectively. Lingnan culture is pragmatic, open, compatible and innovative. In terms of the composition, it includes original native culture, culture in central China and overseas culture. 
Lingnan culture is pragmatic, open, compatible and innovative. Someone intentionally or unintentionally affirmed, "Guangdong is a cultural desert." The msjor cause is that the standard of this sentence is based on Central Plain Culture. In fact, Lingnan culture has formed its own stable characteristics in long-term development process. Cantonese spirit is generalized as "daring to be the first, pragmatic, aggressive, open, compatible and dedicated". In the new period, Cantonese spirit is as follows: "virtuous morality, honest credit and quick action". In Zhuhai cultural construction, it is required to first publicize and consolidate Lingnan culture.

Secondly, Zhuhai has been a city which attaches great importance to education since the end of Wing Dynasty. At that time, Zhuhai was relatively rich and populous; the atmosphere of valuing education rose; some famous academies such as Fengshan Academy (Qianshan), Fengchi Academy (Cuiwei), Ningshan Academy (Sanzao), Jinshan Academy (Xiace) and Hefeng Academy (Doumen). These academies played an important role in inheriting local culture and selecting talents. Then, the earliest batch of children studying abroad appeared in Zhuhai. Thus, Zhuhai is also regarded as the origin place of overseas study in modern China.

Thirdly, Zhuhai does not lack scenic spots and historic sites, such as Maritime Silk Road and Qiao Historical Site since Han Dynasty as well as Shixi Park, Former Residence of Su Manshu, Former Residence of Su Zhaozheng and Tang Guoan Memorial Hall in modern times. However, although Zhuhai government has increased capital input for these cultural scenic spots and enhanced publicity, these scenic spots and historic sites are not attracting. If one place has no historical cultural flavor, it will be like root-free duckweed regardless of the scene of debauchery or elegant and beautiful scenery.

It thus can be seen Zhuhai as an immigrant city is not short of native cultural spirit. The cultural ecology should not be buried and forgotten, but should be protected and publicized. It is required to re-excavate and set cultural ecology to jointly establish cultural spirit of Zhuhai with immigrant culture in the new times.

\section{Build the Future}

In present city construction, it is required to not just pay attention to construction of physical environment, but also focus on construction of cultural environment. During construction of cultural environment of Zhuhai, it is required to utilize traditional cultural resources and take into account of city characteristics of Zhuhai. Cultural tradition of Zhuhai is profound, but still remains developing and utilizing. Meanwhile, Zhuhai is an immigrant city with many colleges. Thus, it is required to construct cultural ecology of Zhuhai for the following aspects:

Firstly, media publicity. "In the information age, communication capacity of culture has become the decisive factor of culture soft power." (Yu, 2011) Communication influences formation of regional culture. During shaping Zhuhai city culture, medial influence should be first paid attention to. Media contribute to forming the sense of identity and advocating favorable social customs.

For residents in Zhuhai, the local news with the highest reliability is Zhuhai TV Station and Zhuhai Daily. In Zhuhai, compared with external media, the acceptance rate and reliability of local media are the highest. In this aspect, Zhuhai media have gained outstanding results.

Over the years, Zhuhai media have enhanced ideological quality construction for news personnel, advanced with the times to grasp direction of public opinions and have obtained excellent results in guiding healthy and civilized life and creating favorable social atmosphere. Zhuhai Daily changed culture supplement to special entertainment edition in order to pursue "fun" and reading rate. Later, it found this page was vulgar and then re-adjusted it in July 2005 to enhance reports of local cultural activities and elegant art. (Lu \& Song, 2006)

Secondly, pay attention to site narration. Baiteng Lake in Zhuhai and West Lake in Hangzhou own similar natural scenery, but West Lake in Hangzhou obviously has more cultural connotation than Baiteng Lake in Zhuhai. In other words, West Lake in Hangzhou bears more symbols of human culture.

In 1970s-1980s, narratology was introduced in urban science field and tried to fuse physical environment and cultural environment to give physical environment cultural significance. In this process, historical information, cultural significance and consciousness of sites are fused together. Place narration should effectively associate materiality factor of a city with narration so as to enhance cultural connotation.

In this aspect, Zhuhai gained many results early. The set-up of Shixi Yilanting Park in Zhuhai reflects protection of ancient cultural relics. Yilanting was built by Bao Jun - a calligrapher in Qing Dynasty. As time passes, damaged walls and pillars were left for Yilanting. Luckily, some historical remains of calligraphy written by Bao Jun were carved on the stones around Yilanting. In 2012, Zhuhai Municipal Government invested in rebuilding Yilanting to protect original stone pillars and walls and re-sketch calligraphy remains. The set-up of Yilanting Park greatly enriches human landscape of Zhuhai. This also reflects site narration. 
The name plays a significant advertising role for a place. In recent years, Zhuhai has put forward to reserve the ancient name. In 2011, Zhuhai proposed Overall planning of street and road names of Zhuhai city (2008-2020) and suggested to adopt old names as far as possible. Zhuhai is a new city in administrative division, but it has a long history. Many old geographical names bear humanity history of Zhuhai and recorded historical rudiment of this place. If these names are abandoned, historical deposits of the place will be deficient greatly. According to the investigations of Ministry of Civil Affairs, some places lack protection awareness for ancient geographical names. The phenomena of changing and abolishing ancient geographical names at will continue despite repeated prohibition. In some historical periods such as "great leap forward" and "the Cultural Revolution" and in the process of accelerated development of urban reconstruction in recent years, many ancient geographical names were abolished. These greatly waste local historical and cultural resources. Paying attention to and reserving old geographical names is a way of site narration and enhances cultural connotation and cultural flavor.

Thirdly, construction of college culture. Chinese universities root in ancient academies which were often in quiet mountain forests with beautiful scenery. Zhuhai is the sole national resort district named after the city. This is beneficial to studying and doing scholarly research. Besides, it is also a city owning the most colleges except Guangzhou.

Urban culture and college culture are interactive. The city is a carrier of colleges. Colleges provide new culture and vigor for the city. Thus, it is required to value the effects of colleges in urban cultural construction. Limited by traditional ideology, colleges often restrict their abilities in the campus and rarely link with the outside. This is to the disadvantage of college construction. On the other hand, it is against promotion of local culture by colleges. Colleges should take the initiative to increase the scope of urban construction.

College libraries should be fully utilized for local cities. College libraries provide favorable reading environment. However, they are seldom open to the society. On the other hand, construction of college libraries is often limited by funds. If college libraries cooperate with local social institutions to share knowledge resources, this can not just gain more capital support, but also promote local cultural construction and make contributions to building a knowledge-based society. During social use of college libraries, it is required to pay attention to city community participation. By contrast, China's city community is still in the initial development stage. The participation awareness of community residents is poor with poor sense of community identity and weak cohesive force. Through participation of college libraries, commonality residents can be organized to add communication and exchange opportunities and create favorable social atmosphere.

In a city, economic modernization does not mean the rise in happiness level. In current times, rapid development of economy, science and technology results in various social problems, i.e. modern anxiety. Especially in China, money worship prevails. When experiencing capital banquet and prosperity, people also feel humane hunger, thirst and infertility. City construction not just includes economy and material, but also includes culture and spirit. Zhuhai is an immigrant city and urban culture is in the initial formation period. Zhuhai has obtained huge achievements in urban appearance and infrastructure and also made good progress in protection and utilization of cultural ecology. However, in the era environment where spiritual civilization generally declines, Zhuhai should make further efforts to maintain the reputation of "the City of Happiness".

\section{References}

Chen, X. (2004, July 12). "Money worship" is not superior to "power worship". Beijing Daily, p. B2.

Lu, Z., \& Song, C. (2006). Public opinion guidance and construction of a harmonious society - practice and exploration of Zhuhai media. Chinese Journalist, (1), 44-45.

Ross, E. A. (1911). The Changing Chinese. New York: The Ridgway Company.

Yang, G., \& Chen, H. (2005). Influence of media contact on local city image - analysis of Zhuhai audience investigation results. Journalism and Communication Studies, (3), 66-75.

Yu, X. (2011). Connotation and Components of Urban Culture Soft Power. Contemporary Communications, (2), 83-85.

Zhu, D. (2010). How does China become the first money-worship country in the world? Brand and Standardization, (9), 33.

Zou, S. (2007). Materialization of spiritual life in modern times and the criticism. Social Sciences in China, (5), 54-63. 


\section{Copyrights}

Copyright for this article is retained by the author(s), with first publication rights granted to the journal.

This is an open-access article distributed under the terms and conditions of the Creative Commons Attribution license (http://creativecommons.org/licenses/by/3.0/). 